\title{
Differences in breaking behavior of rice leaves under microwave and naturally drying processes
}

\author{
Meilin Wang, Zhong Tang*, Ben Zhang, Yu Li \\ (Key Laboratory of Modern Agricultural Equipment and Technology, Ministry of Education, Jiangsu University, \\ Zhenjiang 212013, Jiangsu, China)
}

\begin{abstract}
In order to fight for good farming time or harvest in bad weather, combine harvester will produce more broken leaves when threshing high moisture content rice, which will seriously hinder the grain cleaning effect. In this study, the breaking behavior of rice leaves under different microwave drying time and drying power was studied. Firstly, based on the appearance of freshly rice leaves undergoing microwave drying, the changing property of moisture content, weightlessness rate and temperature rise of rice leaves were tested and analyzed. Secondly, the tensile breaking force of freshly rice leaves under different microwave drying time and drying power was tested and compared with the tensile breaking force of naturally dried rice. Finally, the optimal microwaves parameters of rice leaves after drying which could result in greater breaking force than the natural drying state were obtained. The result showed that microwave drying method will reduce the moisture content of rice leaves and change the microstructure, which would affect the tensile-breaking property of rice leaves. The maximum tensile breaking force of rice leaves appeared at microwave dried power $70 \mathrm{~W}$ for 5-8 min and at microwave dried power $210 \mathrm{~W}$ for 3-4 min. The tensile breaking property of rice leaves at microwave dried power $350 \mathrm{~W}$ for $6-8$ min were the weakest, which was lower than that of fresh rice leaves. Therefore, the optimal microwave drying parameters of rice leaves will provide a basis for the application of microwave technology in the threshing process.
\end{abstract}

Keywords: rice harvesting, rice leaves, microwave drying, moisture content, breaking force DOI: $10.25165 /$ j.ijabe.20221501.6400

Citation: Wang M L, Tang Z, Zhang B, Li Y. Differences in breaking behavior of rice leaves under microwave and naturally drying processes. Int J Agric \& Biol Eng, 2022; 15(1): 89-100.

\section{Introduction}

Rice is the main staple food for half of the population all over the world ${ }^{[1,2]}$. About 160 million $\mathrm{hm}^{2}$ of rice is grown in the world. As a modern rice grain harvesting machine, combine harvester can complete the processes of harvesting, threshing and cleaning at one time ${ }^{[3-5]}$. The weather conditions that prevailed during the harvesting season have an impact on grain loss and quality ${ }^{[6]}$. These conditions are not controllable. However, in order to fight for good farming time or harvest in bad weather, rice in the field will be harvested when it is mature with high water content. Combine harvester will produce a large number of broken leaves during the process of threshing fresh high-moisture rice, which will seriously hinder the cleaning effect of the grain ${ }^{[7,8]}$. However, when the dry rice with lower moisture content was harvested in the field, there was less rice leaves breakage. The size and shape of the broken leaves are different. Since the natural drying time of rice in the field is longer (which is not conducive to farming and harvesting), is there some way to help the rapid drying of rice during the harvest process. If the rice leaf breakage can be reduced during the rice threshing process, this will greatly reduce the difficulty of subsequent grain cleaning. At the

Received date: 2021-01-03 Accepted date: 2021-07-21

Biographies: Meilin Wang, Master candidate, research interest: intelligent harvesting machinery, Email: 1131462006@qq.com; Ben Zhang, Master candidate, research interest: intelligent harvesting machinery, Email: 1035726871@qq.com; Yu Li, Master candidate, research interest: intelligent harvesting machinery, Email: 169909413@qq.com.

*Corresponding author: Zhong Tang, PhD, Associate Researcher, research interest: intelligent harvesting machinery. School of Agricultural Equipment Engineering, Jiangsu University, Zhenjiang 212013, Jiangsu, China. Tel: +86511-88797338, Email: tangzhong2012@126.com. same time, it is of great significance to simplify the grain cleaning device.

Rice threshing process is to thresh and separate the grains from rice ear, but in the threshing process, both rice stalk and rice leaves will be undergoing threshing force. Then combine harvester will produce more broken leaves when threshing high moisture content rice, which will seriously hinder the grain cleaning effect. As the moisture content of the rice plant changes, the breaking force of the rice stalk, rice leaf and grain stalk also changes. At present, many scholars have tested the stalk-breaking force in rice threshing ${ }^{[9-11]}$. They tested the breaking force between rice grains, grain stalks, branch stems, and stalks to obtain the differential property of rice stalk breaking force, which will provide an important basis for rice grain threshing. The morphological characterization of rice leaves and leaf sheaths under different growth conditions is an important parameter to be considered in threshing process. The difference in the structural characteristics of rice leaf sheaths and leaves, and the relationship of size ratio will also affect the content of broken rice leaves after threshing ${ }^{[12]}$. During the rice threshing process, straw is subjected to the force of threshing bar and concave screen. The mechanical of rice stalks and leaves determine the fracture characteristics $^{[13-15]}$. If we need to reveal the relationship between the breaking characteristics of rice leaves and the tensile breaking force after threshing, the tensile breaking force of rice leaves under different maturity conditions needs to be further studied.

The elastic-plastic deformation of rice stalks and leaves is an important factor affecting the fracture during threshing. Lenaerts et al. ${ }^{[16]}$ established a spring-damping discrete element model of wheat stalks and simulated the wheat stalks during threshing, which indicates that the wheat stalk nodes have plastic characteristics. The cross-sections of rice stalks and leaves are honeycomb structures, which makes the stalks being anisotropic 
elastic characteristics. Zhou et al. ${ }^{[17]}$ established a honeycomb structure model of rice stalk cross section, and calculated the anisotropic elasticity of rice stalks by multi-scale simulation method. Then the relationship between the multi-scale structural parameters and elastic modulus of the rice stalks were established. Liu et al. ${ }^{[18]}$ used image analysis to measure the cross-sectional dimensions of rice stalks deformation undergoing stretched state. Many scholars have explored the cross-sectional characteristics, three-dimensional model and deformation characteristics of wheat and rice stalks ${ }^{[7,8,19]}$. However, the breaking mechanism of rice stalks and rice leaves during the threshing process is still unclear. There are many factors influencing the breakage of rice leaves during the rice threshing process ${ }^{[20-22]}$. The mechanism of how threshing parameters affect rice threshing performance is relatively clear. However, it is unclear how the rice plants affect the rice leaf fracture. Rice maturity at the optimal harvest period is an important harvesting indicator. The moisture content of rice leaves during the harvesting process is an important feature of maturity characteristics, which is also an important factor affecting the stalk, rice leaf, and grain stalk breakage. The direct cause of rice stalk and leaf breakage during the threshing process is the threshing force of threshing bars. However, the study of the rice leaf breakage is helpful to find out their fracture factors.

If the fresh rice can be dried quickly during the harvesting process, and its mechanical properties are close to those of naturally dried rice, the breakage of rice leaves will be reduced. The study found that different drying methods have different effects on food quality ${ }^{[23,24]}$. Among them, microwave technology can be used for microwave heating and microwave drying in food processing. It can reduce the moisture of food in a short time ${ }^{[25,26]}$. In recent years, researchers have applied microwave technology to material modification. Scholars at home and abroad have found that microwave destruction of different wood structure elements provided a significant increase in wood permeability for liquids and gases $^{[27]}$. Bruno et al. ${ }^{[28]}$ used low-level microwaves $\left(89 \mathrm{~kW} \cdot \mathrm{h} / \mathrm{m}^{3}\right)$ and high-level microwaves $\left(95 \mathrm{~kW} \cdot \mathrm{h} / \mathrm{m}^{3}\right)$ to treat a batch of green plates. The results showed that the shear strength and compressive strength of the samples after microwave treatment were reduced. High microwaves produce higher intensity reduction and more drying defects than low microwaves. It can be seen that the application of microwave technology can not only reduce the moisture content of rice in a short time but also change the properties of rice leaves by microwave, thereby obtaining rice plants with better mechanical properties.

In view of the serious problem of rice leaves breakage during the threshing process, it is necessary to reduce the content of broken rice leaves in the threshing mixture and explore the behavior of rice leaves breakage. In this study, as fresh rice with high moisture content was microwave dried to complete dehydration, the breaking behavior of rice leaves under different microwave drying times and drying powers were studied. The breaking force of fresh rice under different microwave duration and power was tested and compared with the breaking force of naturally dried rice. Optimal microwaves parameters of rice leaves after drying which could result in greater breaking force than the natural drying state are obtained. Increasing the breaking force of rice leaves by microwave technology can be applied to the threshing process to reduce the rate of broken leaves. It provides a theoretical basis for reducing the problem of the high impurity content of rice threshing mixture. At the same time, it is of great significance to simplify the grain cleaning device.

\section{Materials and methods}

\subsection{Rice leaves morphology}

Rice is a cereal crop of Oryza (Oryza sativa L.). Rice is composed of stalks, leaves, ears, and roots. During the rice harvest period, the moisture content of rice stalks and leaves in the field is $50 \%$ to $65 \%$, and the moisture content of the grain is $15 \%$ to $25 \%$. However, as the maturity of rice stalks in the field increases, the moisture content of the rice stalks and leaves also gradually decreases ${ }^{[21]}$. The moisture content of rice plants in the mature stage gradually decreases with the growth period. Moisture content and morphology of rice stalks and leaves at different maturities are shown in Figure 1.

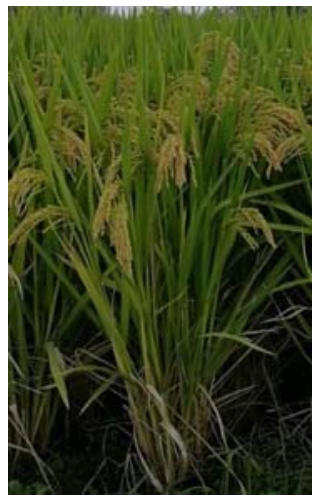

a. Mean moisture content $62 \%$

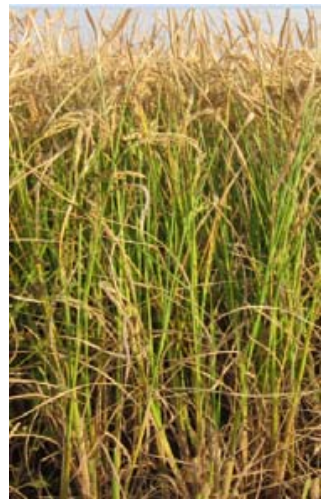

c. Mean moisture content 31\%

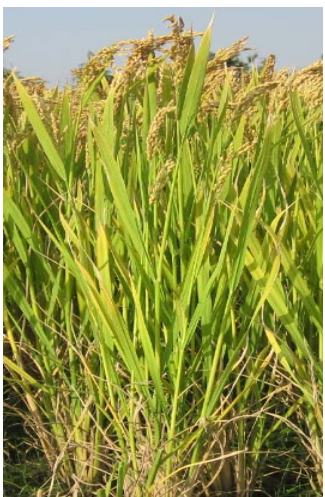

b. Mean moisture content $48 \%$

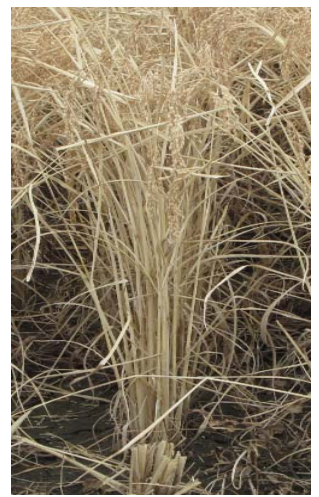

d. Mean moisture content $13 \%$
Figure 1 Moisture content and morphology of rice stalks and leaves at different maturities

Rice leaves are the main organs for photosynthesis. In order to capture solar energy better for photosynthesis to satisfy the needs of its own growth, rice leaves must have a certain rigidity to support their own weight without excessive sagging ${ }^{[29]}$. It should also have sufficient strength and toughness to adapt to its surrounding environment. The complete leaves of rice are composed of leaves, leaf sheaths, leaf tongues, leaf ears, and leaf pillows, and there are obvious veins on the back of the leaves ${ }^{[30]}$. In this study, fresh rice plants were grown in Jiangsu Province, China. Rice was grown in the field with a row spacing of $150 \mathrm{~mm}$ and a distance of $200 \mathrm{~mm}$ between individual rice plants. In the experiment, 5 groups of the same batch of fresh, naturally dried rice leaves were taken as test samples. In order to obtain more accurate water content data, rice leaves were divided into upper, middle, and bottom parts for water content testing. Rice plant morphology is shown in Figure 2. First, the rice was weighed in the fresh state with a high-precision electronic scale. Then, put the rice leaves in Midea's MM721NG1-PW microwave oven on high heat $(700 \mathrm{~W})$ to dry until the quality is no longer reduced. 
Weigh and record the mass before and after the microwave. Calculate the moisture content of the test sample by formula and find the average value. The results show that the moisture content of freshly rice leaves is about $65.45 \%$, and the moisture content of naturally dry rice leaves is $13.10 \%$. The water content $(W)$ calculation equation is as follows:

$$
W=\frac{M_{0}-M_{1}}{M_{0}} \times 100 \%
$$

where, $M_{0}$ is the mass of the test sample before microwave, $\mathrm{g}$; $M_{1}$ is the mass of the test sample after microwave, $\mathrm{g}$.

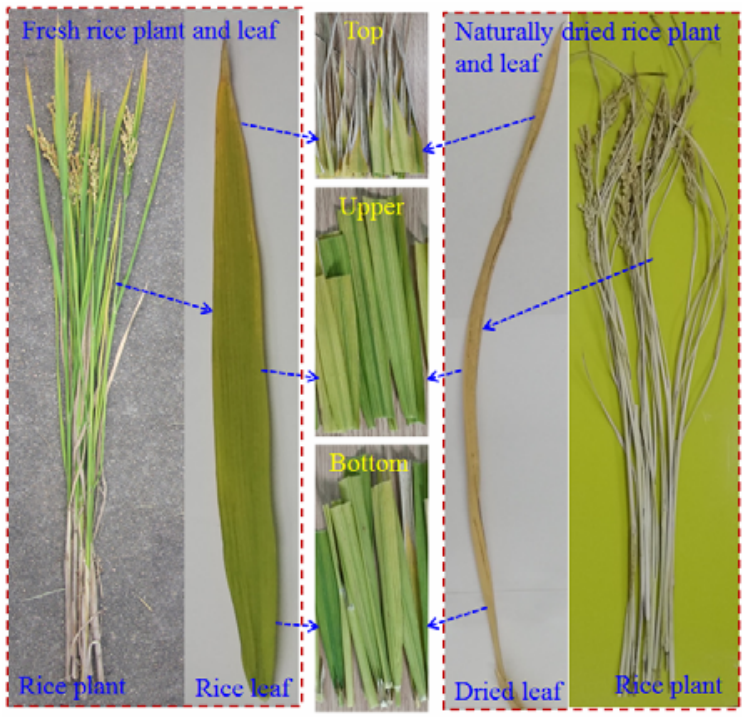

Figure 2 Rice plant and rice leaves morphology

\subsection{Microwave drying method of rice leaves}

Microwave refers to electromagnetic waves with a frequency of $300 \mathrm{MHz}$ to $300 \mathrm{GHz}$, which is the abbreviation of a limited frequency band in radio waves. That is, microwaves are electromagnetic waves with a wavelength between $1 \mathrm{~mm}$ and $1 \mathrm{~m}$. The basic properties of microwaves are penetration, reflection, and absorption. For general glass, plastic, and porcelain, microwaves are almost penetrated and not absorbed, so it is the best utensil for microwave cooking. For water and food, it will absorb microwaves and cause its molecules to oscillate and rub. Thus, microwave energy is converted into heat energy. Microwave treatment of rice leaves can efficiently change the moisture in the leaves in a short time ${ }^{[31]}$. In this study, A Midea MM721NG1-PW microwave oven (made by Guangdong Midea Microwave Manufacturing Co., Ltd., Foshan City, China) is used to dry rice leaves. This microwave oven is mainly composed of six parts, such as magnetron, power transformer, furnace cavity, furnace door, timer, and power distributor.

\subsubsection{Principle of microwave drying}

The microwave heating power used in this experiment is Midea's MM721NG1-PW microwave oven. In daily life, microwave ovens usually use microwaves with a wavelength of $122 \mathrm{~mm}$ and a frequency of $2450 \mathrm{MHz}$. Therefore, limited by the equipment, the controllable factors in the experiment are the microwave power and heating time of the microwave oven.

The microwave oven controls the microwave output by the LC circuit. The microwave output power can only be a constant value, so that the microwave power level adjustment is only converted by controlling the on/off time of microwave transmission. Microwave energy itself is not heated. When a dielectric substance absorbs microwaves, it interacts with the dielectric substance and turns into heat, which causes the substance to heat up.
The relationship between the conversions of microwave energy to heat is as follows:

$$
P_{D}=2 \pi f \varepsilon_{0} \varepsilon_{r} \tan \delta E^{2}
$$

where, $P_{D}$ is the power consumption, $\mathrm{W} / \mathrm{m}^{3} ; E$ is the electric field strength, $\mathrm{V} / \mathrm{m} ; f$ is the frequency, $\mathrm{Hz} ; \varepsilon_{0}$ is the vacuum dielectric constant; $\varepsilon_{r}$ is the relative dielectric constant; $\tan \delta$ is the tangent of dielectric loss angle.

During the drying process, the microwave energy generated by the magnetron is used for material heating, water evaporation, heat convection, and energy loss in the transmission process.

$$
P_{t}=Q_{1}+Q_{2}+\phi t+P_{e} t
$$

The total heat absorbed by the internal temperature of the material during the drying process is as follows.

$$
Q_{1}=c \cdot m \cdot \Delta T
$$

where, $c$ is the specific heat capacity, $\mathrm{J} /\left(\mathrm{g} \cdot{ }^{\circ} \mathrm{C}\right) ; m$ is the quality of rice leaves, $\mathrm{g} ; \Delta T$ is the temperature difference before and after microwave drying, ${ }^{\circ} \mathrm{C}$.

The heat absorbed by water evaporation is as follows:

$$
Q_{2}=q G
$$

where, $q$ is the latent heat of vaporization, $\mathrm{kJ} / \mathrm{kg} ; G$ is the amount of water evaporated, $\mathrm{kg}$.

In the drying process, both electric and magnetic fields cause loss of microwave energy, of which dielectric loss is the main loss of microwave energy. The equation is as follows:

$$
P_{e}=2 \pi f \varepsilon_{0} \varepsilon_{r} \tan \delta E^{2}
$$

where, $P_{e}$ is the dielectric loss power, $\mathrm{W} / \mathrm{m}^{3} ; E$ is the effective electric field strength, $\mathrm{V} / \mathrm{m}$.

The heat transfer power generated by thermal convection is expressed by Newton's cooling Equation.

$$
\phi=h A\left(T_{f}-T_{w}\right)
$$

where, $\phi$ is the heat transfer power, that is, the heat transfer per unit time, $\mathrm{W} ; h$ is the surface convection heat transfer coefficient, $\mathrm{W} /\left(\mathrm{m}^{2} \cdot \mathrm{K}\right) ; A$ is the surface area of rice leaves, $\mathrm{m}^{2} ; T_{f}$ is the air temperature in the microwave, ${ }^{\circ} \mathrm{C} ; T_{w}$ is the surface temperature of the rice leaves in the microwave oven, ${ }^{\circ} \mathrm{C}$.

\subsubsection{Method of microwave drying}

In order to analyze the morphology and tensile difference of rice leaves with different moisture content dried by microwave, freshly rice leaves were dried by microwave oven. The weightlessness rate, moisture content, and temperature of rice leaves under different microwave parameters were tested. In this study, Midea MM721NG1-PW microwave was used to dry fresh leaves. The specific power of the microwave oven for different heat conditions is listed in Table 1.

Table 1 Corresponding power for different fire conditions

\begin{tabular}{clcc}
\hline Rated output power/W & \multicolumn{1}{c}{ Level } & Proportion/\% & Power/W \\
\hline \multirow{4}{*}{700} & Low-fire & 10 & 70 \\
& Medium-low-fire & 30 & 210 \\
& Medium-fire & 50 & 350 \\
& Medium-high-fire & 70 & 490 \\
& High-fire & 100 & 700 \\
\hline
\end{tabular}

Rice leaves include upper and bottom parts. In this study, the upper and bottom parts of rice leaves were used to test the tensile breaking force. Five rice leaves with similar characteristics were selected as a set of test samples. The rice leaves were evenly spread on the tray of the microwave oven and then undergoing microwave drying test with different microwave drying power and microwave drying time. By drying rice leaves for 1-10 min with low-power heat in the microwave oven, the water content of the 
rice leaves can be reduced. The remaining moisture content of rice leaves after microwave can be calculated by testing the mass of rice leaves before and after microwave heating. The tensile breaking force of rice leaves after drying under different microwave power and microwave time was compared with that of naturally dried rice leaves. Rice leaves dried by microwave and test sample of tensile breaking force are shown in Figure 3.

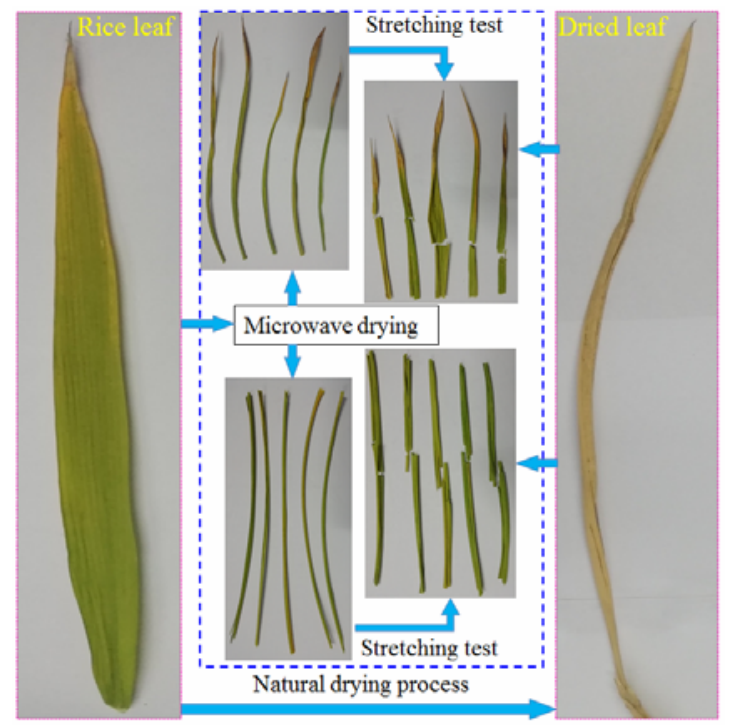

Figure 3 Rice leaves morphology undergoing microwave drying and natural drying

\subsection{Tensile breaking force test method of rice leaves}

The ability of rice leaves resistant to tensile force is an important indicator reflecting the causes of leaves breaking after threshing ${ }^{[32]}$. In order to test the tensile breaking force of rice leaves dried by microwave with different power and different time, the device used for the tensile tests of rice leaves was the Edgar 0824 push-pull testing machine (made by China Shenzhen Xindeya Precision Instrument Co., Ltd., Shenzhen, China). Rice leaf tensile test device and method is shown in Figure 4. Its test and analysis software can display the tensile force of rice leaves in real-time. After the test, the data can be processed and analyzed later. The parameters of Edgar 0824 tensile testing device are listed in Table 2.

Table 2 Parameters of Edgar 0824 tensile testing device

\begin{tabular}{lc}
\hline \multicolumn{1}{c}{ Parameter } & Value \\
\hline Model & HP-200 \\
Test distance accuracy $/ \mathrm{mm}$ & 0.1 \\
Test force accuracy $\%$ & 0.5 \\
Sensors & Built-in pressure sensor \\
Test distance range $/ \mathrm{mm}$ & $0.1-180.0$ \\
Power range $/ \mathrm{kg}$ & $+/-20$ \\
PC interface & RS $232 \mathrm{C}$ standard port or USB port \\
Operating temperature $/{ }^{\circ} \mathrm{C}$ & -20 to 70 \\
\hline
\end{tabular}

The main steps of the tensile force test of the two ends of rice leaves are pulled vertically. Firstly one end of freshly rice leaf is clamped; then the push-pull test device is calibrated and adjusted to zero; finally pulling force is applied to the specimen and the data can be obtained. All samples were tested under the loading rate of $1 \mathrm{~mm} / \mathrm{s}$. The same method can also be used to microwave dried rice leaves and naturally dried rice leaves. The tensile force test method for rice leaves is shown in Figure 4.

\subsection{Microstructure testing of rice leaves}

In order to compare and analyze the microstructural changes of freshly rice leaves, microwave dried rice leaves, and naturally dried rice leaves, the microscopic morphology of rice leaves cross section was observed using an opto-platinum optical electron microscope WN25VY (China New Bell Technology Co., Ltd.). This electron microscope could achieve a magnification test of $\times 2000$. The observed sample could be displayed on the high-definition screen. Images of the microstructure could be stored on a PC through an interface. The opto-platinum optical electron microscope is shown in Figure 5.

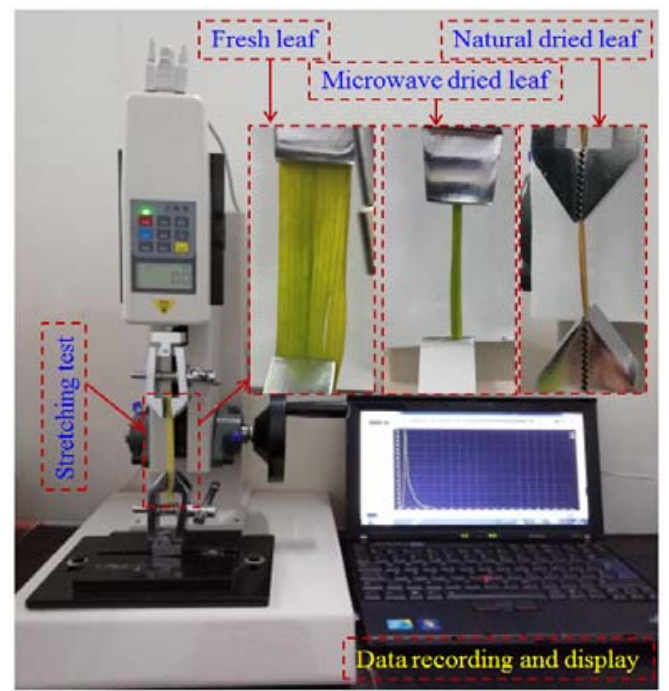

Figure 4 Rice leaves tensile breaking force test device and method

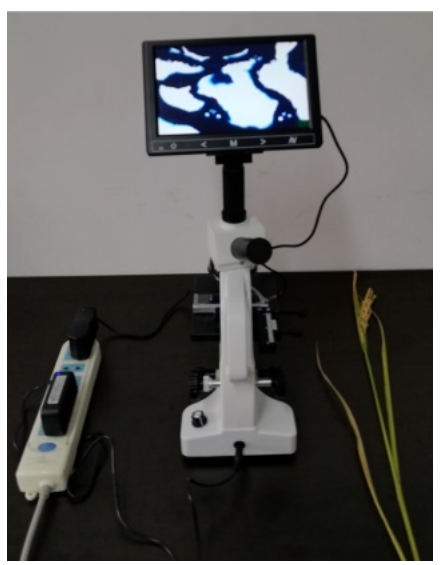

Figure 5 Opto-platinum optical electron microscope

Complete pieces of freshly rice leaves, microwave dried rice leaves, and naturally dried rice leaves were chosen to be test samples. Thin samples of rice leaves were cut with a sharp knife. Rice leaves have a multilayer structure, thus each epidermis of rice leaves was observed using a combination of $\times 25$ eyepiece and $\times 10$ objective lens. The rice leaves of freshly rice leaves, microwave dried rice leaves, and naturally dried rice leaves were observed in the same manner to analyze the difference of microstructure characteristics. The rice leaves were observed in a similar method to rice stems.

\section{Results and discussion}

\subsection{Morphology and microstructure of rice leaves}

There are three basic structures of rice leaves, which were epidermis, mesophyll and leaf vein. The vascular bundles in the leaves are arranged in parallel, and there are vesicular cells between the vascular bundles of the upper epidermis ${ }^{[12,33]}$. In order to investigate whether the macroscopic morphology and microstructure of rice leaves are different under different states, 
morphology and microstructure difference of microwave dried, naturally dried and fresh rice leaves were comparatively analyzed by electron microscope. The morphology and microstructure differences of microwave dried, naturally dried and fresh rice leaves were shown in Figure 6. The photomicrographs of rice leaves before and after microwave drying were tested and analyzed to clarify the influence of the changes in the microstructure on the mechanical properties.

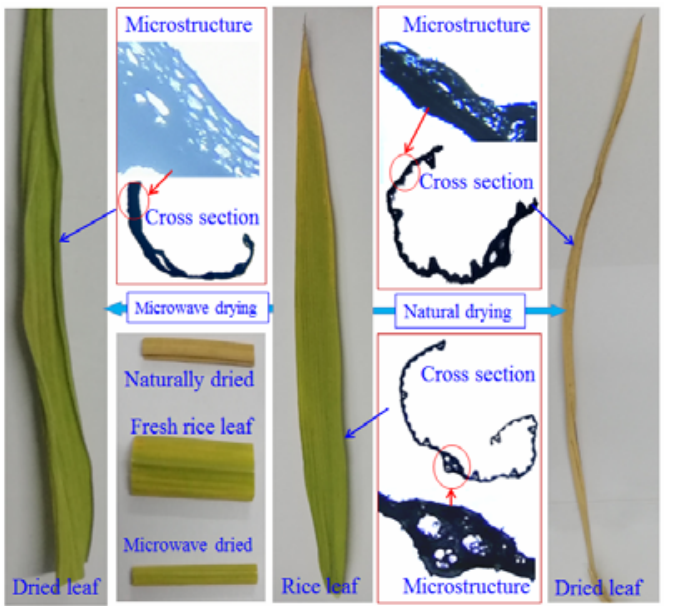

Figure 6 Morphology and microstructure difference of microwave dried, naturally dried and fresh rice leaves

According to Figure 6, the macroscopic morphology of freshly rice leaves appears green due to chlorophyll. The rice leaf is both light and thin. After the fresh leaves are dried by microwave, the vesicular cells of the upper epidermis shrink with water loss, making the leaves shrink and curl from the lower surface to the upper surface ${ }^{[34]}$. At the same time, the rice leaves were bent, and the color did not change significantly. As the microwave power or time increases, the degree of blade curl becomes deeper, and then different degrees of bending occur in a cylindrical shape. When the rice leaves lose too much water, the rice leaves become lighter in color and more brittle. In the natural dried state, the rice leaves contract toward the main veins due to water loss, and then they appear yellow due to the disappearance of chlorophyll.

According to Figure 6, the microstructure of the cell boundaries cannot be seen clearly. The morphology and number of mesophyll cells cannot be observed specifically. The air cavity and vascular bundle are clearly visible. Due to the high moisture content of freshly rice leaves, their cells are in a state of expansion. In order to better observe the microstructure of the cross-section of the rice leaf in the natural dry state with a microscope, the rice leaf is artificially flattened. When most water of rice leaves is lost, the vascular bundle is showing a hollow state. The cells in the rice leaves shrink leading the plasma wall separated. The vascular bundle, cell wall and other structures have not changed significantly. The rice leaf structure is still intact. Microscopic observation results of the cross-section of rice leaves under microwave heating showed that the rice leaves were curled. Some cell structures of rice leaves were broken. When the microwave power is large or the microwave time is long, the cell rupture is more obvious. The distribution of water in the cell changes significantly, and the ratio of free water to bound water becomes smaller. With the increase of microwave power and microwave time, microwaves cause irreparable damage to the cell wall. Sun et al. ${ }^{[35]}$ microscopically observed the changes in the fiber structure of Artemisia stalks before and after microwave drying. Their results showed that the fiber structure of the stem after microwave drying would be changed from dense to thin. Lyu et al. ${ }^{[36]}$ used microwave-hot air vibrating fluidized bed dryer to treat bitter gourd flakes. At a magnification of 300 times, it was observed that the microwave dried tissue structure was completely destroyed. It shows that the cell wall was severely damaged after being stimulated. The composition of the cell wall and the ratio of the cell wall components play an important role in the mechanical properties of the stem ${ }^{[13]}$. Therefore, the destruction of the cell wall will cause changes in the mechanical properties of the rice leaves, thus affecting the breaking rate of the rice leaves during the threshing process.

\subsection{Property change of rice leaves dried by microwave}

\subsubsection{Changes in weightlessness rate and temperature rise}

Due to a large amount of free water being inside the rice leaves, it is easier to evaporate and diffuse. The weightlessness rate of rice leaves dried by microwave is shown in Figure 7a.

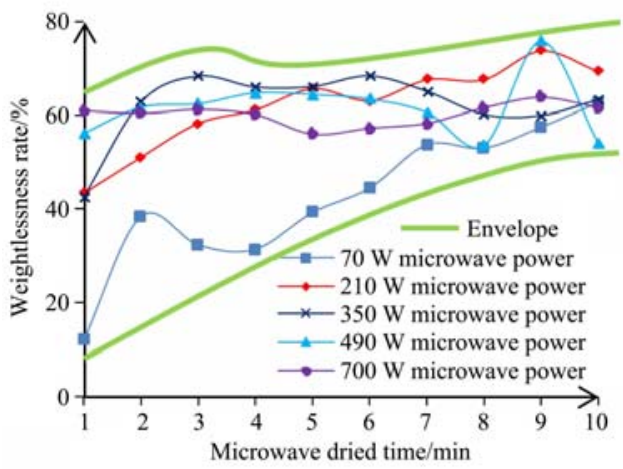

a. Changes in weightlessness rate

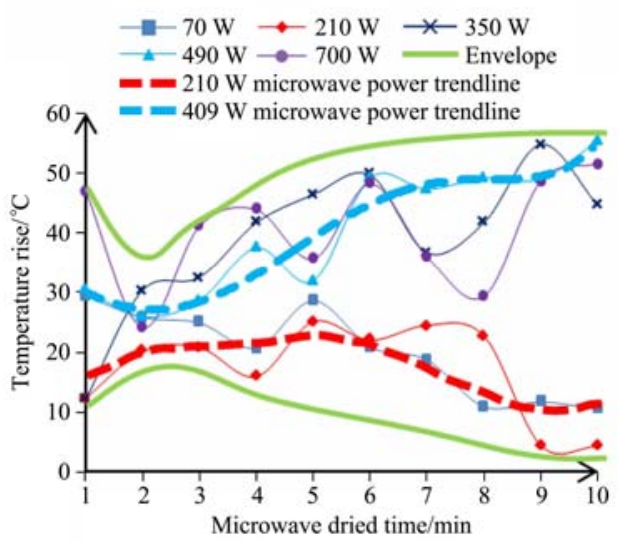

b. Changes in temperature rise

Figure 7 Property change of rice leaves dried by microwave

According to Figure $7 \mathrm{a}$, in the microwave dried process of rice leaves, the weightlessness rate changes at two stages. Firstly, the weightlessness rate increased with the increasing process of microwave drying time. Secondly, the weightlessness rate of rice leaves was basically stable. 1) In the early stage of microwave drying, the weightlessness rate of rice leaves gradually increased. During the microwave drying processing, the free water being inside the rice leaves becomes less. Most of the water in rice leaves was lost at this stage. The results showed that the moisture content of rice leaves is about $61.70 \%-69.33 \%$. At the same time, the greater the microwave power, the more obvious the change in rice leaf weight loss rate. 2) In the late stage of microwave drying, the weightlessness rate of rice leaves tended to be stable. In this stage, the water of rice leaves was mainly bound water. However, the water evaporation of rice leaves would be difficult as the proportion of combined water is increasing. When the microwave was finished, the moisture content of rice leaves could become $0 \%$. 
When rice leaves were dried by microwave, the microwave penetrates into the rice leaves. The free water of rice leaves migrates outward. If microwave drying is continued after excessive water losses, the internal structure of rice leaves would be destroyed. At this time, the mechanical properties of rice leaves would be changed.

When the rice leaves were dried by microwave, the surface temperature of rice leaves before and after microwave processing were tested and compared. The surface temperature rise of rice leaves is shown in Figure 7b. As the microwave time increases, the surface temperature rise property of rice leaves can be divided into two states.

1) When the microwave dried powers were $70 \mathrm{~W}$ and $210 \mathrm{~W}$, the surface temperature rise of rice leaves showed a trend of first increasing and then slowly decreasing. The surface temperature rise would be the maximum value when the microwave time was $2 \mathrm{~min}$. The surface temperature rise of rice leaves was $25.8^{\circ} \mathrm{C}$ in 2 min with microwave dried power $70 \mathrm{~W}$. Similarly, when rice leaves were dried by microwave power $210 \mathrm{~W}$ within $2 \mathrm{~min}$, the surface temperature would be $20.1^{\circ} \mathrm{C}$. So, rice leaves absorb microwave energy and convert it into heat energy, which causes the blade temperature to rise. Within $2 \mathrm{~min}$ of the low-power microwave, most of the microwave energy was used to raise the surface temperature of the rice leaves. When the microwave drying time is more than $2 \mathrm{~min}$, water vaporization would take away most of the heat. Then the temperature rise shows a downward trend.

2) When the microwave dried powers were $350 \mathrm{~W}, 490 \mathrm{~W}$ and $700 \mathrm{~W}$, the surface temperature rise of rice leaves showed a trend of decreasing first and then increasing. The surface temperature rise would be minimum value when the microwave time was $2 \mathrm{~min}$. In $2 \mathrm{~min}$, the surface temperature rises of rice leaves were $30.3^{\circ} \mathrm{C}$, $25.9^{\circ} \mathrm{C}$, and $24.1^{\circ} \mathrm{C}$ with microwave dried power $350 \mathrm{~W}, 490 \mathrm{~W}$ and $700 \mathrm{~W}$, respectively. So, a large amount of moisture in the leaves would be quickly vaporized with high microwave dried power. During the high microwave power drying process, most of the microwave energy was used to evaporate water in rice leaves. Only a small amount was used to increase the surface temperature of rice leaves. When the microwave drying time is more than 2 min, most of the water in the rice leaves has been lost. A small part of the microwave energy is used to evaporate residual water in the rice leaves. That is said most microwave energy is used to increase the surface temperature of the rice leaves. The surface temperature property of rice leaves shows an upward trend. In general, the surface temperature rise of rice leaves is trumpet-shaped, firstly shrinks and then diverges. The range of surface temperature change is within the envelope. So, the turning point of the surface temperature change of rice leaves induced by microwave drying is $2 \mathrm{~min}$. These results showed that the microwave power level has the opposite effect on the surface temperature changing trend.

\subsubsection{Changes in moisture content of rice leaves}

In order to analyze the effect of different microwave dried power and microwave dried time on the moisture content of rice leaves, the rice leaves were microwave dried at different microwave powers for 1-10 min, and then the moisture content was calculated. The moisture content distribution of rice leaves at different microwave dried powers and dried times is shown in Figure 8 .

According to Figure 8, the higher the microwave drying power is, the faster the moisture content of rice leaves decreases. Only in areas near the abscissa (microwave power axis) and near the ordinate (microwave drying time axis), the moisture content of rice leaves is greater than zero. In other areas, the water content is close to zero. It showed that with the increase of microwave dried power, the time required for decreasing the moisture content of rice leaves is less. Therefore, both microwave power and microwave time will affect the moisture content of rice leaves.

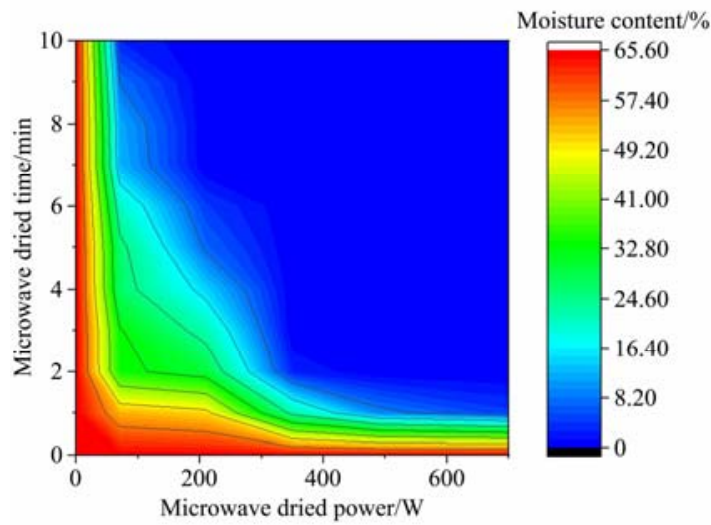

Figure 8 Moisture content distribution of rice leaves at different microwave dried powers and dried times

When the rice leaves were dried by microwave, fresh rice leaves convert the microwave energy into heat energy by absorbing microwave energy. So that the temperature inside and outside the rice leaves rises almost simultaneously. Because the surface temperature of the rice leaf rises rapidly in a short time, the water in the vascular bundle and the cell cavity of rice leaf will vaporize and drain through the cell wall. However, the internal structure of rice leaves will not change. With the increase of microwave drying power or the increase of microwave drying time, the water content in the rice leaves decreased to 0 . Liu et al. ${ }^{[37]}$ used scanning electron microscopy, changed in the microstructure of larch wood due to microwave irradiation were analyzed. The results showed that high-intensity microwave treatment effectively penetrates the narrow channels of larch wood. It can be seen that microwave will damage the microstructure of rice leaves and affect their tensile properties.

During the natural drying process of rice leaves, freshly rice leaves gradually lose water due to transpiration. The heat transfer and mass transfer processes between the leaves and air are relatively slow, so the temperature of water in rice leaves cell cavity rises slowly. The volume of evaporation and expansion is limited. It is considered that the migration of water in this process is slowly diffused to the outside of the leaf according to the change of the moisture content gradient. The moisture content decrease rate in the natural drying process is very slow, which will take a long time. Because of the air humidity, the moisture content of rice leaves in the natural dry state cannot be reduced to zero. Therefore, the moisture content and microstructure of rice leaves in the microwave-dried state and the natural-dried state are different, resulting in significant differences in their mechanical properties.

\subsection{Tensile breaking force curve of rice leaves}

In order to analyze the breaking property of freshly rice leaves, microwave dried rice leaves, and naturally dried rice leaves, the tensile breaking force of rice leaves upper part and bottom part were tested. The tensile breaking force curve of the upper part of freshly rice leaves, microwave dried rice leaves, and naturally dried rice leaves are shown in Figure 9. The tensile breaking force curve of the bottom part of freshly rice leaves, microwave dried rice leaves, and naturally dried rice leaves are shown in Figure 10. 


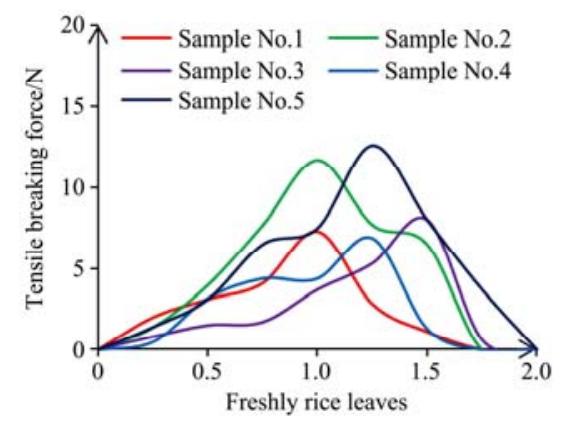

a. Freshly rice leaves

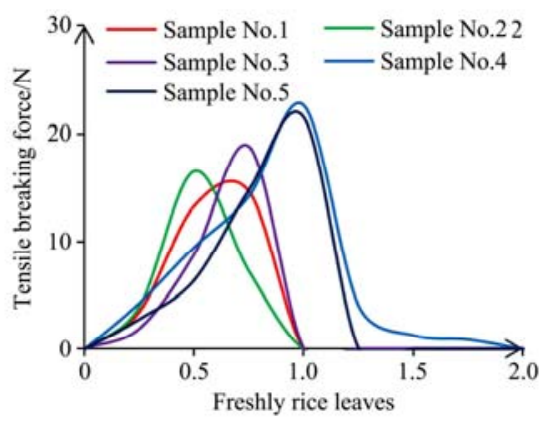

b. Microwave dried rice leaves

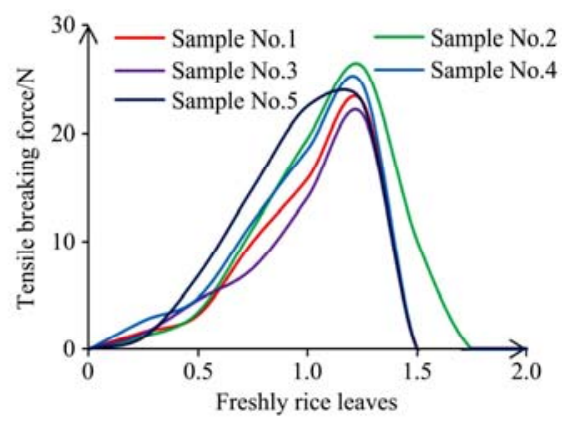

c. Naturally dried rice leaves

Figure 9 Tensile breaking force curve of rice leaves upper part

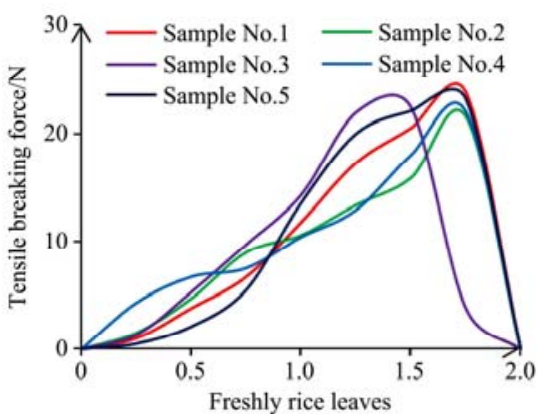

a. Freshly rice leaves

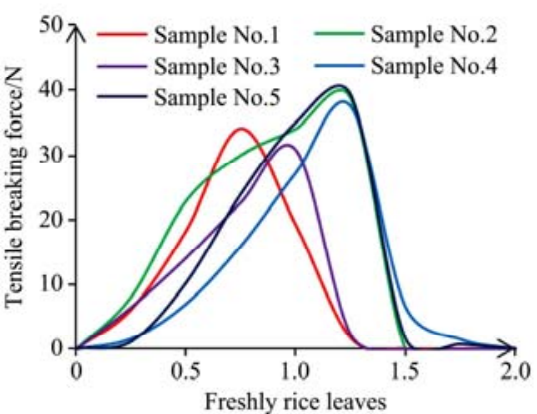

b. Microwave dried rice leaves

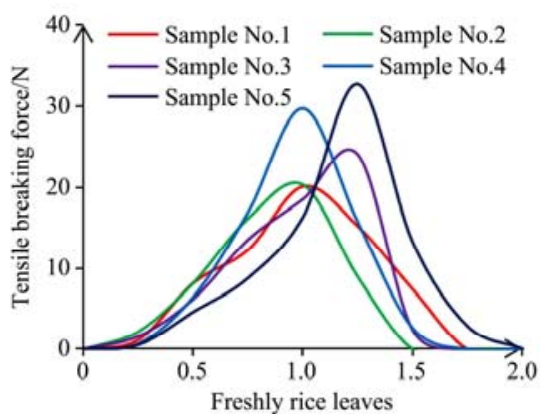

c. Naturally dried rice leaves

Figure 10 Tensile breaking force curve of rice leaves bottom part

As shown in Figures 9 and 10, when fresh leaves were undergoing axial tension, rice leaves were completely broken. The broken shape of rice leaf was irregular. The tensile breaking force curve showed a rapid rise in the early stage and then a sudden decrease after the fracture. During the tensile breaking process, the expansion of water in the cell produces stress that causes damage to the vascular bundle, cell wall, and other structures ${ }^{[37]}$. The test samples of microwave dried rice leaves were obtained by heating fresh rice leaves with $70 \mathrm{~W}$ microwave power for $3 \mathrm{~min}$. The tensile breaking force curve showed a rapid rise in the early stage and then a sudden decrease after the fracture. This is basically consistent with the tensile-breaking force curve of fresh rice leaves. When naturally dried rice leaves were undergoing axial tension, the breakage was mainly at the clamping point. The fracture shape was oblique tearing with irregular fracture edge. The tensile-breaking force curve showed a trend of rapid rise in the early stage and then a sudden drop after the fracture. It showed that the vascular bundle, cell wall and other structures had not been microscopically destroyed. During the tensile breaking process, the stress that caused the destruction of the cell structure was lacking, so its tensile capacity was significantly higher than that of fresh rice leaves. The test results of the peak tensile breaking force of rice leaves in different states are shown in Table 3.

Table 3 Peak tensile breaking force of rice leaves in different states

\begin{tabular}{clccc}
\hline \multicolumn{2}{c}{ Rice leaves } & Range/N & Average value/N & Variance \\
\hline \multirow{3}{*}{ Upper part } & Freshly & $6.9-18.1$ & 10.58 & 22.90 \\
& Microwave dried & $14.6-22.6$ & 18.80 & 11.17 \\
& Naturally dried & $21.8-26.3$ & 23.67 & 5.50 \\
\hline \multirow{3}{*}{ Bottom part } & Freshly & $21.6-23.8$ & 22.60 & 1.24 \\
& Microwave dried & $30.8-39.2$ & 36.04 & 12.47 \\
& Naturally dried & $20.1-55.0$ & 31.98 & 5.17 \\
\hline
\end{tabular}

Besides, the tensile breaking force of rice leaves bottom part is significantly higher than that of the upper part of rice leaves. This is mainly because the rice leaf vein is a porous structure composed of vascular bundles and surrounding tissues. During the tensile breaking process, the veins are mainly responsible for the tensile force. The veins presented in the upper part of rice leaves are smaller, so, the tensile strength is weaker. This is consistent with the experimental results of $\mathrm{Li}$ et al. ${ }^{[38]}$ on the tensile properties of the main veins and mesophyll of poplar leaves. Xie et al. ${ }^{[39]}$ conducted longitudinal tensile, lateral tensile, impact shear, and moisture content correlation tests on the bract leaf physical and mechanical properties, and they carried out bract leaf peeling mechanical tests based on the mechanical property tests. Tension is an important indicator that reflects the breaking property of crops. Due to differences in crop varieties and growth properties, the test results also were slightly different. But the test method and the changing property were similar.

In order to analyze the influence of microwave drying method and temperature control on the moisture or tensile properties of rice leaves, the thermostat treatment and $350 \mathrm{~W}$ microwave drying of the bottom part of the rice leaves were compared in this study. The result is shown in Figure 11.

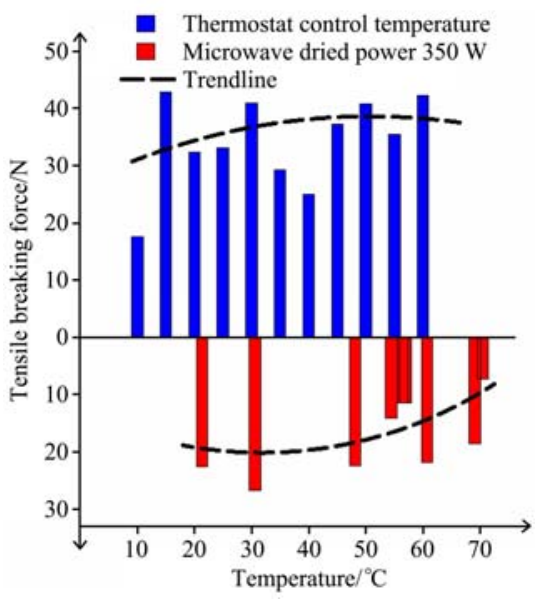

Figure 11 Tensile breaking force of rice leaves deal with thermostat and microwave dried 
As shown in Figure 11, the tensile strength of rice leaves is different at different temperatures. The moisture content of rice leaves after the thermostat treatment is close to that of the fresh state. It showed that the thermostat only changes the temperature of the rice leaf surface within a certain range, which is little effect on the moisture content. Its tensile properties showed a tendency of decrease after rising, and then the tensile capacity reached its optimum at $35^{\circ} \mathrm{C}$. The peak tensile breaking force of the bottom part of freshly rice leaves was $22.6 \mathrm{~N}$. Therefore, when the moisture content of rice leaves is consistent, the temperature of rice leaf controlled by thermostat will change the tensile breaking force property to some extent.

The surface temperature of rice leaves before microwave drying is $18.5^{\circ} \mathrm{C}$. After the rice leaves were dried at microwave power $350 \mathrm{~W}$ for $1-8 \mathrm{~min}$, the surface temperature of rice leaves ranged from $21.3^{\circ} \mathrm{C}$ to $70.5^{\circ} \mathrm{C}$. When microwave dried rice leaves were undergoing axial tension, the maximum peak tensile breaking force of rice leaves is $26.64 \mathrm{~N}$. It appeared 1 minute after microwave drying. At this time, the moisture content of the rice leaves after microwave drying was $22.89 \%$. Thus apparent contrast, microwave drying method can increase the temperature of rice leaves while reducing the moisture content of rice leaves. The moisture content change of rice leaves after microwave drying will affect the tensile-breaking properties of the rice leaves. The decrease in the moisture content of rice leaves will cause the tensile strength of the rice leaves to weaken, which is because its microstructure may be destroyed by microwave drying. For example, when rice leaves were dried by microwave, the cell wall is broken, which would change the tensile breaking property. Tang et al. ${ }^{[40]}$ carried out the tensile test of rice leaves under different temperatures and moisture. The results showed that moisture content had a greater impact on rice leaf breaking property. When the temperature of rice leaves was $-10^{\circ} \mathrm{C}$ to $65^{\circ} \mathrm{C}$, the tensile breaking force at different temperatures in the bottom part of rice leaves showed an upward trend firstly and then a downward trend.

\subsection{Difference in tensile breaking force property}

In order to analyze the influence of microwave drying power and time on the tensile properties of rice leaves, the tensile breaking force of the upper and bottom of rice leaves dried under different microwave drying power and time was tested.

\subsubsection{Tensile property of microwave dried power $70 \mathrm{~W}$}

The tensile breaking force of rice leaves was tested to analyze the tensile property. The microwave dried power was $70 \mathrm{~W}$, which could change the moisture content of rice leaves. The difference of tensile breaking force property was compared with different dried states of freshly rice leaves, microwave dried rice leaves, and naturally dried rice leaves. The tensile breaking force property of rice leaves dried by microwave power $70 \mathrm{~W}$ is shown in Figure 12.

As shown in Figure 12, with the increase of microwave time, the tensile breaking force of rice leaves showed a trend of rising first and then falling both for the upper and bottom parts of rice leaves. The maximum tensile breaking force of rice leaves was about 4-5 min, which was greater than that of naturally dried rice leaves. When rice leaves were dried by microwave for 5-8 $\mathrm{min}$, the moisture content was $11.75 \%$ to $26.27 \%$. When rice leaves are undergoing microwave drying for 1-8 min, the moisture content of rice leaves will decrease as the microwave drying time increases. At this time, the tensile breaking force of rice leaves dried by microwave was greater than that of naturally dried rice leaves that were also greater than that of fresh leaves. During the microwave drying process of rice leaves, the moisture content of rice leaves gradually decreases. However, the tensile breaking force range of rice leaves decreases first and then increases. It can be seen that the tensile-breaking force property can be changed by microwave drying.
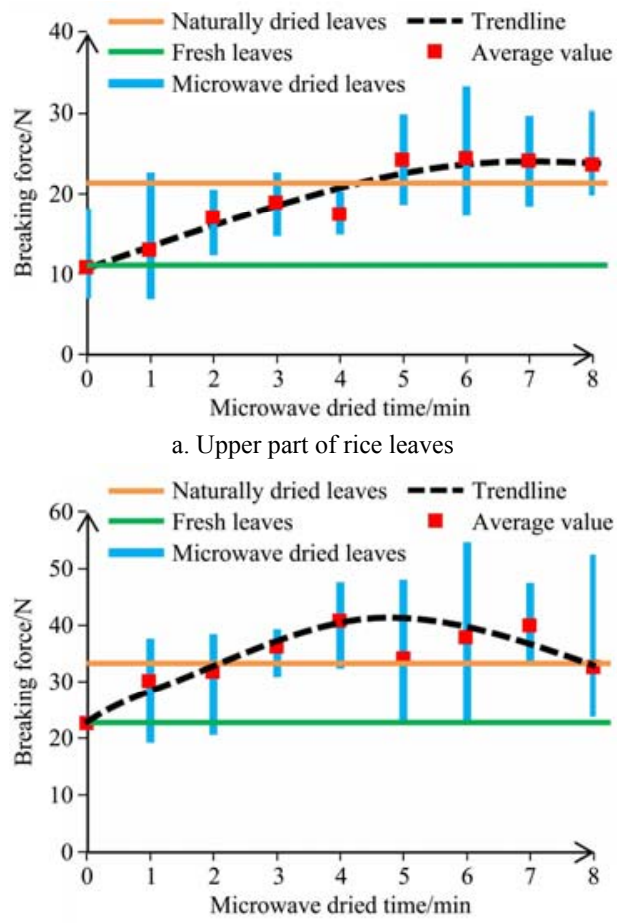

b. Bottom part of rice leaves

Figure 12 Tensile breaking force property of rice leaves dried by microwave power $70 \mathrm{~W}$

\subsubsection{Tensile property of microwave dried power $210 \mathrm{~W}$}

Compared with low microwave, high microwave will produce higher intensity reduction and more drying defects ${ }^{[28]}$. The tensile breaking force property of rice leaves dried by microwave power $210 \mathrm{~W}$ is shown in Figure 13.
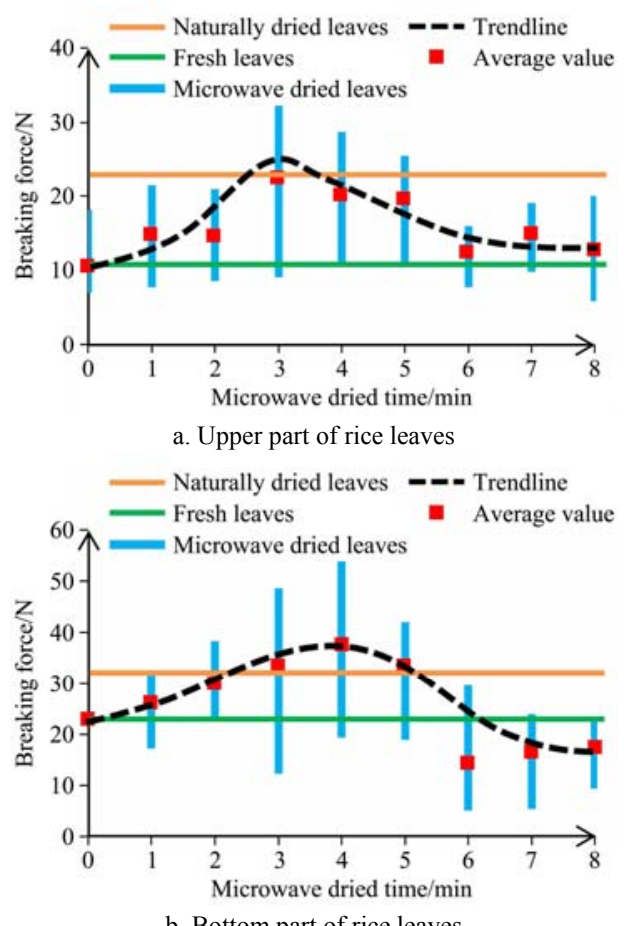

Figure 13 Tensile breaking force property of rice leaves dried by microwave power $210 \mathrm{~W}$ 
As shown in Figure 13, the tensile breaking force of rice leaves showed a trend of rising first and then falling both for the upper and bottom parts of rice leaves. The maximum tensile breaking force of rice leaves upper part was $22.48 \mathrm{~N}$, which was appeared at microwave drying for $3 \mathrm{~min}$. However, it took $4 \mathrm{~min}$ to reach the maximum tensile breaking force for the bottom part of rice leaves. At this time, the maximum tensile breaking force was $37.54 \mathrm{~N}$. When rice leaves are undergoing microwave drying for 1-8 min, the moisture content of rice leaves will decrease as the microwave drying time increases. The moisture content of rice leaves was closed to 0 at $7 \mathrm{~min}$ dried by microwave power $210 \mathrm{~W}$, and then the tensile breaking force of rice leaves upper part and bottom part were $14.86 \mathrm{~N}$ and $16.30 \mathrm{~N}$, respectively. When the rice leaves are dried by microwave for 3-4 min, the tensile breaking force of rice leaves is greater than that of naturally dried rice leaves. During the microwave drying process of rice leaves, the moisture content of rice leaves gradually decreases. However, the tensile breaking force range of rice leaves increases first and then decreases. There was a maximum tensile breaking force point of rice leaves which was produced by microwave drying.

3.4.3 Tensile property of microwave dried power $350 \mathrm{~W}, 490 \mathrm{~W}$ and $700 \mathrm{~W}$

At other higher microwave drying power (Such as $350 \mathrm{~W}$, $490 \mathrm{~W}$, and $700 \mathrm{~W}$ ), the difference of tensile breaking force property was compared with different dried states of freshly rice leaves, microwave dried rice leaves, and naturally dried rice leaves. The tensile breaking force property of rice leaves dried by microwave power $350 \mathrm{~W}$ is shown in Figure 14a.

The tensile breaking force property of rice leaves dried by microwave power $490 \mathrm{~W}$ is shown in Figure 14b.

The tensile breaking force property of rice leaves dried by microwave power $700 \mathrm{~W}$ is shown in Figure 14c.
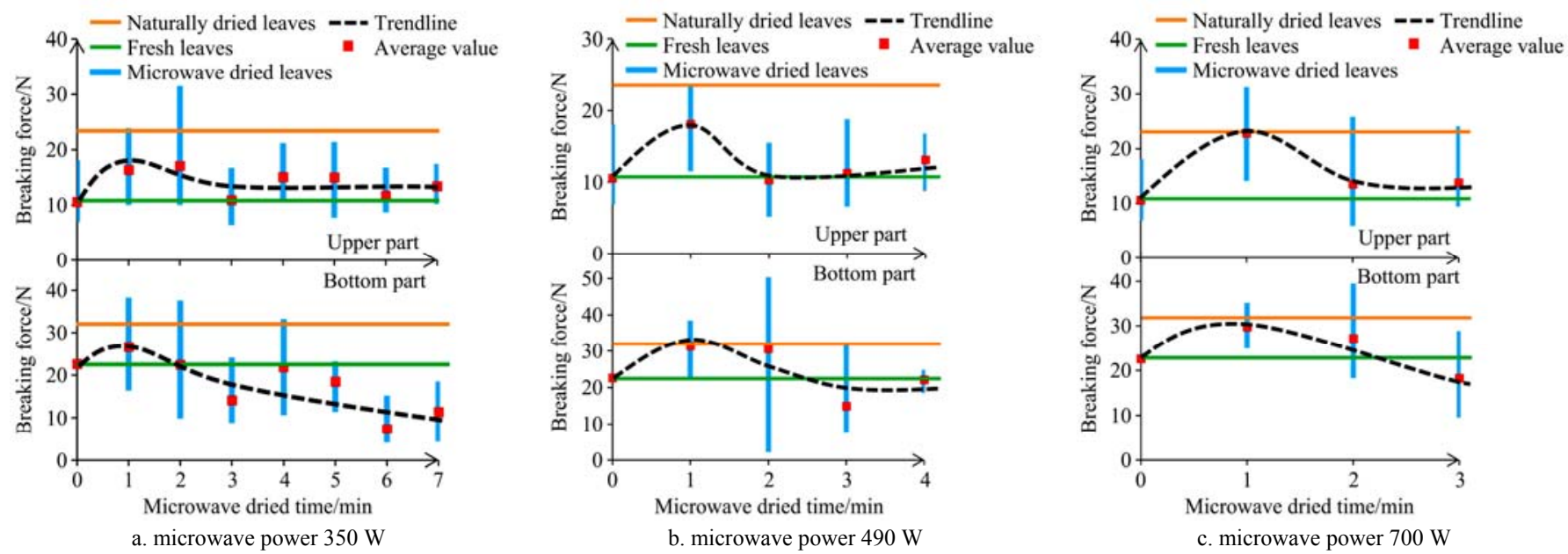

Figure 14 Tensile breaking force property of rice leaves dried by microwave power $350 \mathrm{~W}, 490 \mathrm{~W}, 700 \mathrm{~W}$

As shown in Figure 14, there were similar results for tensile breaking force property and moisture content changing property to that of microwave dried power $70 \mathrm{~W}$ and $210 \mathrm{~W}$. During the microwave drying process of rice leaves, the moisture content of rice leaves gradually decreases. The tensile breaking force of rice leaves showed a trend of rising first and then falling both for the upper and bottom parts of rice leaves. However, the maximum tensile breaking force point of rice leaves was not obtained by tested results. The maximum tensile breaking force points were between $0-1 \mathrm{~min}$, which was obtained by prediction. So, the tensile breaking force property can be changed by microwave drying. We can predict that there was a maximum tensile breaking force point of rice leaves which was produced by microwave drying.

\subsection{Tensile property induced by microwave power}

In order to analyze the influence of different microwave dried power and microwave dried time on the tensile property of rice leaves, the tensile breaking force of upper part and bottom part of rice leaves were tested. According to Figures 12-14, the tensile breaking force of upper part and bottom part of rice leaves induced by different microwave dried power and microwave dried times are listed in Table 4.

Table 4 Tensile breaking force of rice leaves induced by microwave power

\begin{tabular}{|c|c|c|c|c|c|c|c|c|c|}
\hline \multirow{2}{*}{ Rice leaves } & \multirow{2}{*}{$\begin{array}{l}\text { Microwave dried } \\
\text { power/W }\end{array}$} & \multicolumn{8}{|c|}{ Microwave dried time/min } \\
\hline & & 1 & 2 & 3 & 4 & 5 & 6 & 7 & 8 \\
\hline \multirow{5}{*}{$\begin{array}{l}\text { Upper } \\
\text { part }\end{array}$} & 0 & 10.58 & 10.58 & 10.58 & 10.58 & 10.58 & 10.58 & 10.58 & 10.58 \\
\hline & 70 & 12.86 & 16.88 & 18.80 & 17.36 & 24.12 & 24.34 & 24.03 & 23.50 \\
\hline & 210 & 14.75 & 14.65 & 22.48 & 20.04 & 19.62 & 12.38 & 14.86 & 12.66 \\
\hline & 350 & 16.35 & 17.12 & 10.93 & 15.04 & 15.00 & 11.72 & 13.38 & 13.38 \\
\hline & 700 & 22.84 & 13.53 & 13.76 & 13.76 & 13.76 & 13.76 & 13.76 & 13.76 \\
\hline \multirow{5}{*}{$\begin{array}{l}\text { Bottom } \\
\text { part }\end{array}$} & 0 & 22.60 & 22.60 & 22.60 & 22.60 & 22.60 & 22.60 & 22.60 & 22.60 \\
\hline & 70 & 29.95 & 31.60 & 36.04 & 40.63 & 33.87 & 37.67 & 39.70 & 32.43 \\
\hline & 210 & 25.92 & 29.86 & 33.32 & 37.54 & 33.20 & 14.10 & 16.30 & 17.22 \\
\hline & 350 & 26.64 & 22.44 & 14.12 & 21.83 & 18.50 & 7.33 & 11.40 & 11.40 \\
\hline & 490 & 31.34 & 30.58 & 14.92 & 22.08 & 22.08 & 22.08 & 22.08 & 22.08 \\
\hline
\end{tabular}


When rice leaves were dried by microwave power $70 \mathrm{~W}$ for 1-8 min, the tensile breaking force of rice leaves was much more like the natural drying process. The tensile breaking force of fresh rice leaves undergoing microwave power $70 \mathrm{~W}$ for 1 to 8 min were tested and analyzed. Tensile breaking force values of rice leaves undergoing microwave power $70 \mathrm{~W}$ for $1-8 \mathrm{~min}$ are listed in Table 5 .

Table 5 Tensile breaking force of rice leaves undergoing microwave power $70 \mathrm{~W}$

\begin{tabular}{cccccccc}
\hline $\begin{array}{c}\text { State of } \\
\text { rice leaves }\end{array}$ & $\begin{array}{c}\text { Microwave dried } \\
\text { time/min }\end{array}$ & \multicolumn{4}{c}{$\begin{array}{c}\text { Tensile breaking } \\
\text { force/N }\end{array}$} & $\begin{array}{c}\text { Average } \\
\text { value }\end{array}$ \\
\hline $\begin{array}{c}\text { Fresh rice } \\
\text { leaves }\end{array}$ & -- & 7.3 & 18.1 & 8.0 & 6.9 & 12.6 & 10.58 \\
\hline & 1 & 6.8 & 22.6 & 13.7 & 6.8 & 14.4 & 12.86 \\
& 2 & 19.3 & 17.4 & 12.2 & 15.0 & 20.5 & 16.88 \\
Microwave & 3 & 14.6 & 16.5 & 18.8 & 22.6 & 21.5 & 18.80 \\
dried & 4 & 15.6 & 17.2 & 20.3 & 18.9 & 14.8 & 17.36 \\
power & 5 & 29.9 & 19.4 & 18.6 & 29.2 & 23.5 & 24.12 \\
$70 W$ & 6 & 22.3 & 33.2 & 29.3 & 17.2 & 19.7 & 24.34 \\
& 7 & 18.4 & 29.7 & 24.5 & 23.5 & 24.03 & 24.03 \\
& 8 & 23.2 & 19.8 & 30.2 & 23.50 & 20.8 & 23.50 \\
\hline $\begin{array}{c}\text { Natural dry } \\
\text { rice leaves }\end{array}$ & -- & 22.9 & 20.1 & 26.3 & 27.3 & 21.8 & 23.67 \\
\hline
\end{tabular}

According to Table 3 and Table 4, the average value of the tensile breaking force of the upper part of the rice leaves was 10.32-24.34 N. The average value of the tensile breaking force of the bottom part of rice leaves were 7.33-40.63 N. When the moisture content of rice leaves is 0 , there is no obvious change in the tensile property of rice leaves in a short time. Therefore, the tensile breaking force of rice leaves undergoing microwave power $350 \mathrm{~W}$ for 7-8 min, undergoing microwave power $490 \mathrm{~W}$ for $4-$ $8 \mathrm{~min}$, and undergoing microwave power $700 \mathrm{~W}$ for 3-8 min remains unchanged.

Based on the results of Table 3, the contour map of tensile breaking force of upper part and bottom part of rice leaves induced by different microwave dried power and microwave dried times are shown in Figure 15.

As shown in Figure 15a, the tensile breaking force of the upper part of the rice leaves showed a decreasing trend from the peak to the surroundings. The peak value of tensile breaking force appeared at microwave dried power $70 \mathrm{~W}$ for drying $6 \mathrm{~min}$. The average value of tensile breaking force of the upper part of rice leaves undergoing the microwave dried power $70 \mathrm{~W}$ for $5-8 \mathrm{~min}$ is larger. That is the tensile strength of the upper part of rice leaves is strong. The tensile capacity of the upper part of rice leaves undergoing microwave dried power $350 \mathrm{~W}$ for $3 \mathrm{~min}$ and undergoing microwave dried power $490 \mathrm{~W}$ for 2-3 min was similar to that of the freshly dried state.

As shown in Figure 15b, the tensile breaking force of the bottom part of rice leaves showed a decreasing trend from the peak to the surroundings. The peak value of tensile breaking force appeared at microwave dried power $70 \mathrm{~W}$ for $4 \mathrm{~min}$. The average tensile breaking force of the bottom part of rice leaves was higher at microwave dried power $70 \mathrm{~W}$ for $4 \mathrm{~min}$ and $7 \mathrm{~min}$, and also at microwave dried power $210 \mathrm{~W}$ for 3-4 min. That is the tensile strength of the bottom part of rice leaves is strong. The tensile strength of the bottom part of rice leaves undergoing microwave dried power $350 \mathrm{~W}$ for 6-8 min was significantly lower than that of the freshly dried state.

In order to compare the tensile breaking force distribution of rice leaves undergoing different microwave dried power and microwave heating time, the results of Table 3 are drawn as a polar plot. Tensile breaking force distribution of rice leaves undergoing different microwave dried power and times was shown in Figure 16.

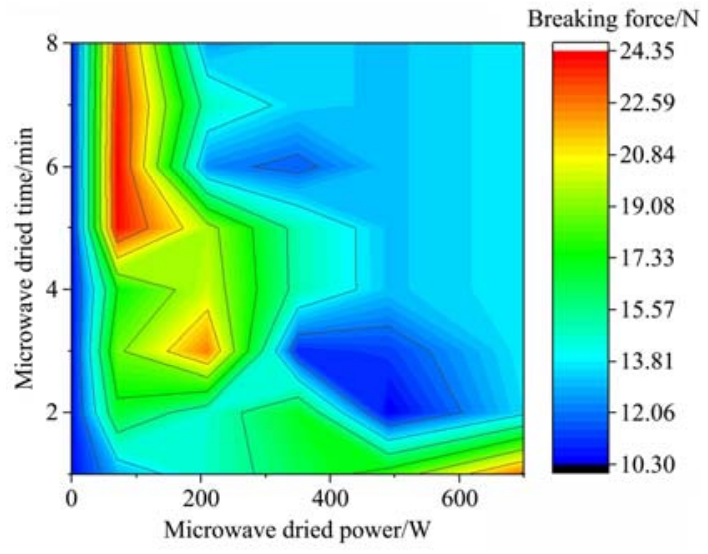

a. Upper part of rice leaf

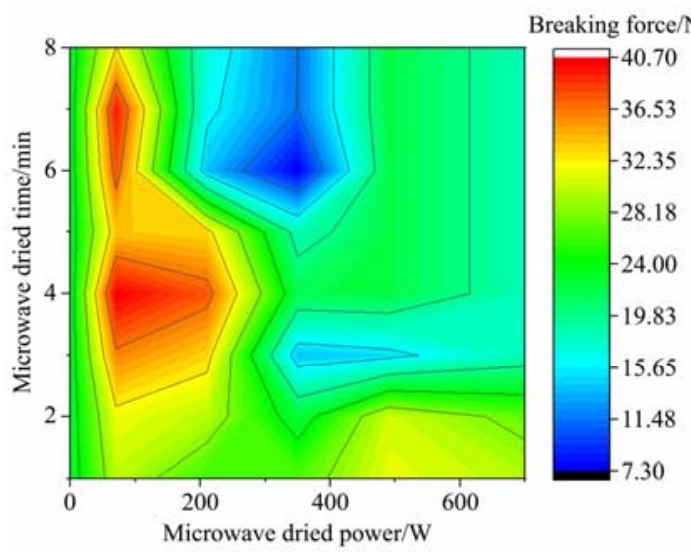

b. Bottom part of rice leaf

Figure 15 Contour map of tensile breaking force induced by different microwave dried power and times

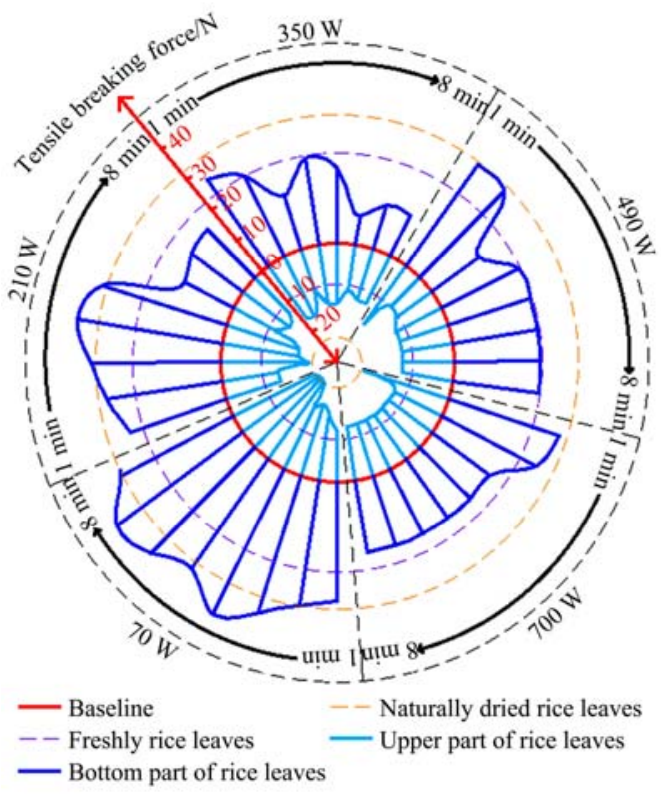

Figure 16 Tensile breaking force distribution of rice leaves undergoing different microwave dried power and times

As shown in Figure 16, inside the baseline is the tensile breaking force of the upper part of rice leaves. Outside the baseline is the tensile breaking force of the bottom part of rice leaves. The upper part of rice leaves has the strongest tensile 
strength undergoing microwave dried power $70 \mathrm{~W}$ for $5 \mathrm{~min}$. The bottom part of rice leaves has the strongest tensile strength undergoing microwave dried power $70 \mathrm{~W}$ for $4 \mathrm{~min}$ and $7 \mathrm{~min}$, and also undergoing microwave dried power $70 \mathrm{~W}$ for 3-4 min. When rice leaves were dried by microwave for 1-8 $\mathrm{min}$, the tensile breaking force of the upper part of rice leaves is always higher than that of the upper part of fresh rice leaves, while the bottom part of rice leaves can be weakened by microwave drying. So, the tensile breaking force property can be changed by microwave drying. It can be predicted that there was a maximum tensile breaking force point of rice leaves which was produced by microwave drying.

\section{Conclusions}

1) Fresh rice leaves are flat. However, rice leaves in a naturally dry state and after microwave dried are curled. In the microwave dried process of rice leaves, the weightlessness rate changes are increasing with the increasing process of microwave drying time, and then is basically stable. As the drying time is increasing, the moisture content of rice leaves gradually decreases to 0 . The higher the microwave drying power, the faster the moisture content of rice leaves decreases. When the microwave drying powers were $70 \mathrm{~W}$ and $210 \mathrm{~W}$, the surface temperature rise of rice leaves showed a trend of first increasing and then slowly decreasing. When the microwave dried powers were $350 \mathrm{~W}$, $490 \mathrm{~W}$ and $700 \mathrm{~W}$, the surface temperature rise of rice leaves showed a trend of decreasing first and then increasing.

2) Tensile breaking force of naturally dried rice leaves with a moisture content of $13.10 \%$ is significantly higher than that of fresh leaves with a moisture content of $65.45 \%$ at a constant temperature. The microwave drying method can increase the temperature of rice leaves while reducing the moisture content of rice leaves. The moisture content change of rice leaves after microwave drying will affect the tensile breaking properties of the rice leaves. The tensile breaking force of rice leaves bottom part is significantly higher than that of the upper part of rice leaves. The peak value of the tensile breaking force at the upper part of rice leaves was 6.9-18.1N. The peak value of critical tensile breaking force at the bottom part of rice leaves was 21.6-23.8 N.

3) When rice leaves are dried by microwave, the tensile breaking force of rice leaves showed a trend of rising first and then falling both for the upper and bottom part of rice leaves. It can be seen that the tensile breaking force property can be changed by microwave drying. There was a maximum tensile breaking force point of rice leaves induced by microwave drying, which is greater than that of naturally dried state. The tensile capacity of the upper part of rice leaves undergoing microwave dried power $350 \mathrm{~W}$ for $3 \mathrm{~min}$ and undergoing microwave dried power $490 \mathrm{~W}$ for 2-3 $\mathrm{min}$ was similar to that of the naturally dried state.

\section{Data Availability}

The data used to support the findings of this study are available from the corresponding author upon request.

\section{Acknowledgements}

This research work was financially supported by the National Natural Science Foundation of China (Grant No. 52175235), Jiangsu Province "Six Talents Peak" High-level Talent Project (GDZB-085), Single Technology Research and Development Project of Jiangsu Agricultural Science and Technology Innovation Fund (CX(21)3144), Open Fund of Jiangsu Key Laboratory of Agricultural Equipment and Intelligent High Technology
(JNZ201912), and Jiangsu Province Research and Practice Innovation Program Project (KYCX21_3382).

\section{[References]}

[1] Ali W, Mao K, Zhang $\mathrm{H}$, Junaid $\mathrm{M}$, Xu N, Rasool A, et al. Comprehensive review of the basic chemical behaviors, sources, processes, and endpoints of trace element contamination in paddy soil-rice systems in rice-growing countries. Journal of Hazardous Materials, 2020; 397: 1-24.

[2] Zhu D F, Cheng S H, Zhang Y P. Analysis of status and constraints of rice production in the world. Scientia Agricultura Sinica, 2010; 43(3): 474-479.

[3] Tang Z, Zhang B, Wang B, Wang M L, Chen H, Li Y M, Breaking paths of rice stalks during threshing. Biosystems Engineering, 2021; 204: 346-357.

[4] Tang Z, Zhang B, Wang M L, Zhang H T. Damping behaviour of a prestressed composite beam designed for the thresher of a combine harvester. Biosystems Engineering, 2021; 204:130-146.

[5] Busato P, Berruto R. Minimising manpower in rice harvesting and transportation operations. Biosystems Engineering, 2016; 151: 435-445.

[6] Khir R, Atungulu G, Chao D, Pan Z L. Influences of harvester and weather conditions on field loss and milling quality of rough rice. Int $\mathrm{J}$ Agric \& Biol Eng, 2017; 10(4): 216-223.

[7] Tang Z, Li Y M, Li X Y, Xu T B. Structural damage modes for rice stalks undergoing threshing. Biosystems Engineering, 2019; 186: 323-336.

[8] Miao C, Wang Z, Zhang L, Yao J, Hua K, Liu X, et al. The grain yield modulator miR156 regulates seed dormancy through the gibberellin pathway in rice. Nature Communications, 2019; 10(1): 1-12.

[9] Tang Z, Li Y, Li X Y, Xu T B. Structural damage modes for rice stalks undergoing threshing. Biosystems Engineering, 2019; 186: 323-336.

[10] Tang Z, Li Y M, Xu L Z. Assessment of rice threshing and separation performance for just mature rice and over mature rice. International Agricultural Engineering Journal, 2014; 23(4): 44-51.

[11] Wang Z M, Lyu P M, Chen N, Ma G. Study on distribution spectrum of grain connection force and differential-speed threshing device for combine harvester. Journal of Zhejiang University, 2017; 43(1): 120-127.

[12] Toriba $T$, Tokunaga $H$, Shiga $T$, Nie F, Naramoto S, Honda E, et al. BLADE-ON-PETIOLE genes temporally and developmentally regulate the sheath to blade ratio of rice leaves. Nature Communications, 2019; 10(1): $1-13$.

[13] Muhammad A, Hao H H, Xue Y L, Alam A, Wang L. Survey of wheat straw stem characteristics for enhanced resistance to lodging. Cellulose, 2020; 27(5): 2469-2484.

[14] Singh S, Mackill D J, Ismail A M. Responses of SUB1 rice introgression lines to submergence in the field: yield and grain quality. Field Crops Research, 2009; 113(1): 12-23.

[15] Du D D, Wang J. Research on mechanics properties of crop stalks: A review. Int J Agric \& Biol Eng, 2016; 9(6): 10-19.

[16] Lenaerts B, Aertsen T, Tijskens Et, De Ketelaere B, Ramon H, De Baerdemaeker J, et al. Simulation of grain-straw separation by DEM with bendable straw particles. Computers and Electronics in Agriculture, 2014; 101(1): 24-33.

[17] Zhou F, Huang J L, Liu W Y, Deng T, Jia Z K. Multiscale simulation of elastic modulus of rice stem. Biosystems Engineering, 2019; 187: 96-113.

[18] Liu Y P, Lin X, He T H, Kong C Q, Li G H. Mechanical properties measurement and statistical analysis of paddy stem based on image analysis method. Journal of Experimental Mechanics, 2012; 27(4): 421-427.

[19] Tang Z, Liang Y Q, Zhang B, Wang M L, Zhang H, Li Y M. Effects of multi-sequence combination forces on creep characteristics of bales during wheat harvesting. International Journal of Agricultural and Biological Engineering, 2021; 14(5): 88-99.

[20] Amponsah S K, Addo A, Dzisi K A, Moreira J, Ndindeng S A. Performance evaluation and field characterization of the Sifang Mini Rice combine harvester. Applied Engineering in Agriculture, 2017; 33(4): 479-489.

[21] He P F, Li J, Zhang D Q, Wan S. Optimisation of the harvesting time of rice in moist and non-moist dispersed fields. Biosystems Engineering, 2018; 170: 12-23.

[22] Govindaraj M, Masilamani P, Asokan D, Rajkumar P, Selvaraju P. Effect of different harvesting and threshing methods on seed quality of rice varieties. International Journal of Current Microbiology and Applied 
Sciences, 2017; 6(8): 2375-2383.

[23] Wei Q Y, Huang J P, Zhang Z Y, Lia D J, Liu C Q, Xiao Y D, et al. Effects of different combined drying methods on drying uniformity and quality of dried taro slices. Drying Technology, 2019; 37(3): 322-330.

[24] Kroehnke J, Szadzińska J, Stasiak M, Radziejewska-Kubzdela E, Biegańska-Marecik R, Musielak G. Ultrasound-and microwave-assisted convective drying of carrots - Process kinetics and product's quality analysis. Ultrasonics sonochemistry, 2018; 48: 249-258.

[25] Zielinska M, Zielinska D, Markowski M. The effect of microwave-vacuum pretreatment on the drying kinetics, color and the content of bioactive compounds in Osmo-Microwave-Vacuum dried cranberries (Vaccinium macrocarpon). Food and Bioprocess Technology, 2018; 11(3): 585-602.

[26] Cao X H, Chen J P, Islam M N, Xu W X, Zhong S Y. Effect of intermittent microwave volumetric heating on dehydration, energy consumption, antioxidant substances, and sensory qualities of litchi fruit during vacuum drying. Molecules, 2019; 24(23): 4291. doi: 10.3390/ molecules24234291.

[27] Terziev N, Daniel G, Torgovnikov G, Vinden P. Effect of microwave treatment on the wood structure o Norway spruce and radiata pine. Bioresources, 2020; 15(3): 5616-5626.

[28] Balboni B M, Ozarska B, Garcia J N. Microwave treatment of Eucalyptus macrorhyncha timber for reducing drying defects and its impact on physical and mechanical wood properties. European Journal of Wood and Wood Products, 2018; 76(3): 861-870

[29] Altamimi N, Brien C, Oakey H, Berger B, Saade S, Ho Y S, et al. Salinity tolerance loci revealed in rice using high-throughput non-invasive phenotyping. Nature Communications, 2016; 7(1): 13342-13342.

[30] Beuzelin J M, Meszaros A, Way M O, Reagan T E. Rice harvest cutting height and ratoon crop effects on late season and overwintering stem borer (Lepidoptera: Crambidae) infestations. Crop Protection, 2012; 34(34): $47-55$.
[31] Huang L L, Qiao F, Fan D M. Microstructure changing and moisture removing of lychee during microwave vacuum drying. International Int J Agric \& Biol Eng, 2016; 9(3): 162-169.

[32] Huang J, Liu W, Zhou F, Peng Y. Effect of multiscale structural parameters on the mechanical properties of rice stems. Journal of the Mechanical Behavior of Biomedical Materials, 2018; 82: 239-247.

[33] Zhang H, Wu Z, Wang C, Li Y, Xu J. Germination and infectivity of microconidia in the rice blast fungus Magnaporthe oryzae. Nature Communications, 2014; 5(1): 4518-4518.

[34] Kang X, Kirui A, Widanage M C, Mentinkvigier F, Cosgrove D J, Wang T. Lignin-polysaccharide interactions in plant secondary cell walls revealed by solid-state NMR. Nature Communications, 2019; 10(1): 1-9.

[35] Sun W, Mu X K, Sun Q C, Huang M, Li S H, Huang X. Effects of microwave drying on mechanical properties of wormwood stem. Transactions of the CSAE, 2015; 31(10): 277-282. (in Chinese)

[36] Lyu H, Lyu H Z, Yang B N, Lyu W Q, Du Z L. Moisture and heat characteristics and apparent form of Balsam Pears in microwave-hot-airflow vibrating bed drying. Transactions of the CSAM, 2020; 51(4): 373-381. (in Chinese)

[37] Liu M L, Li C F, Wang Q W. Microstructural characteristics of larch wood treated by high-intensity microwave. Bioresources, 2019; 14(1): $1174-1184$

[38] Li X J, Liang Y H, Zhang Z H, Ren L Q. Microstructure and tensile property of poplar Ponulus hopeiensis leaves. Journal of Jilin University (Engineering and Technology Edition), 2012; 42(S1): 440-443. (in Chinese)

[39] Xie F X, Song J, Huo H X, Hou X X. Experiment and mechanical characteristics on bract peeling of corn harvester. Journal of Agricultural Mechanization Research, 2018; 40(8): 129-133. (in Chinese)

[40] Tang Z, Li Y, Zhang B, Wang M L, Li Y M. Controlling rice leaf breaking force by temperature and moisture content to reduce breakage. Agronomy, 2020; 10(5): 628. doi: 10.3390/agronomy10050628. 